\title{
Research on subassembly Flow-Line of curved panel based on Simulation Technology
}

\author{
Li Ming-Ming, Wang Yue, Li Cui-Cui
}

\begin{abstract}
With the rapid development of industrial informationization, the technological revolution represented by intelligent manufacturing is gradually subverting the traditional labor-intensive shipbuilding industry. It not only brings lower labor costs, higher product quality, but also greatly reduce the periods of shipbuilding. The era that shipbuilding enterprise's competitiveness is largely depend on labor costs will never go back. Compare with the rapid development of foreign shipbuilding in intelligent shipbuilding, the upgrade of Chinese shipbuilding enterprises is obviously lagging behind, among them, the manufacture of ship curved block is the most outstanding, it still stays in the manual operation stage that relies on a large amount of manual operation. Therefore, the reformation of the curved block workshop is of great significance to Chinese shipbuilding enterprises. This paper use the subassembly Flow-Line of curved panel as a breakthrough to upgrade the curved block production, and by means of simulation technology, verifies the rationality and feasibility of the curved block assembly shop after transformation.
\end{abstract}

Index Terms - Flow-Line; curved panel; Simulation Technology

\section{INTRODUCTION}

the "Industry 4.0"[1] proposed by Germany has caused widespread resonance around the world. Countries have successively put forward their own manufacturing development strategies to promote the transformation and upgrading of the manufacturing industry. Humans are accelerating toward the era of industrial intelligence, and as a traditional labor-intensive industry, the shipbuilding industry is also inevitably impacted. Emerging information technology is gradually infiltrating into the shipbuilding field. At present, advanced foreign shipbuilding enterprises continue to promote the construction of intelligent shipyards on the basis of digital, automation and lean production modes. However, due to the non-standardization and customization characteristics of ship products, the intellectualized development of shipbuilding industry is lagging behind that of automobiles and construction machinery and other manufacturing industries. However, in the long run, intelligent manufacturing is an inevitable trend in the development of the shipbuilding industry [2].

in-depth analysis of the shipbuilding level of Chinese shipyards. reveals that under the existing shipbuilding mode, many shipyards have high automated production in raw

Li Ming-Ming, School of Naval Architecture \& Ocean Engineering, Jiangsu University of Science and Technology, Zhenjiang, Jiangsu, China

Wang Yue, School of Naval Architecture \& Ocean Engineering, Jiangsu University of Science and Technology, Zhenjiang, Jiangsu, China Li Cui-Cui, School of Petrochemical and Energetic Engineering, Zhejiang Ocean University, Zhoushan, Zhejiang, China material pretreatment, parts processing and assembly, sheet metal forming etc. At the level, individual shipyards even initially formed intelligent assembly line [3]. However, the larger intermediate products in the shipbuilding process still use traditional production methods that rely on a large amount of manpower. There is a huge gap in production rhythm between processes, which seriously restricts the improvement of the overall manufacturing level of shipyards. The transformation of the curved block production is one of the most urgent needs of Chinese shipbuilding enterprises. In the existing mode, the construction of curved block has long been the "bottleneck" in the whole shipbuilding process: the curved block manufacturing occupies a considerable proportion in the process of ship construction, its construction hours account for $30 \%$ of the total construction hours of the ship, and the planar block of parallel production has basically realized pipelined and efficient production. Therefore, the restrictive effect of low production efficiency of curved block in shipbuilding is particularly prominent. The Flow-Line production of curved block has become a subject that must be faced, and it is also the general trend under the transformation and upgrading of Chinese shipbuilding industry.

As an important part of the hull structure, the research on curved block has been continued for many years. However, due to the long-term low cost and adequate manpower environment, the process of mechanization, automation and intellectualization of curved block assembly shop in china is still lagging behind seriously, as a result, the current academic research is limited to the framework of Fixed-Location production mode. ZHANG Zhi-ying et al [4] combined the Fixed-Location production and Flow-Line production mode, propose a virtual Flow-Line operation mode, that is to say, in the production process of fixed workstation with curved block, the organization form of Flow-Line operation is adopted; $\mathrm{Li}$ Jingsheng et al [5] combine spatial scheduling problems that satisfy both time and space constraints with Flow-Line, and the spatial layout method for curved block was given by combining the collision test with optimal screen. Tang Weidong [6] regards the resource entropy as the criterion of resource balance, combined with the virtual Flow-Line of construct curved block. The problem of resource scheduling equilibrium in the process is studied; Mao Zujie [7] further integrates the concept of lean shipbuilding into the curved block virtual Flow-Line, and applies it to the actual shipyard.

\section{DESIGN OF SUBASSEMBLY LINE OF CUVED PANEL}

Traditional Fixed-Location production mode is widely used in curved block construction in Chinese shipbuilding enterprises. It is to place the base of the curved block on a fixed platform, Operators and equipment assemble or weld 
various parts on the base around the fixed workstation, and finally form the required curved blocks. Fixed-Location curved block construction site is shown in Figure 1.

To renovate the current curved block assembly shop, this paper extensively refers to the solutions of advanced shipbuilding enterprises in the word. but due to high cost, differences in shipbuilding modes and gaps in design and management levels, advanced curved block Flow-Line can't transplanted to Chinese shipbuilding enterprises, in other words, Chinese shipyards do not yet have the conditions to establish curved block assembly Flow-Line at present. However, on the other hand, the development of the shipbuilding industry urgently requires the transformation and upgrading of the curved block production, therefore, this paper decides to reform some "intermediate products" in the production process of curved block. Considering comprehensively, this paper separates the curved panel production from the production line of curved block, and establishes the subassembly Flow-Line of curved panel.

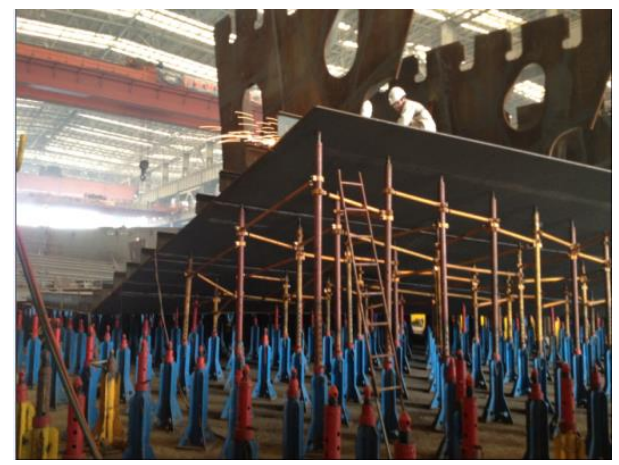

Figure 1 Constructing curved block in Fixed-Location mode

\section{A. Process settings}

The movable bed-jigs[8]makes it possible to realize subassembly Flow-Line of curved panel, that is to say, the bed-jigs is placed on the platform which can move along the track, and the platform is moved to each workstation for processing, new automatic and intelligent equipment are applied in each workstation, therefore, it is very important to set up the process flow and corresponding workstation of subassembly Flow-Line of curved panel. Movable bed-jigs are shown in Figure 2.

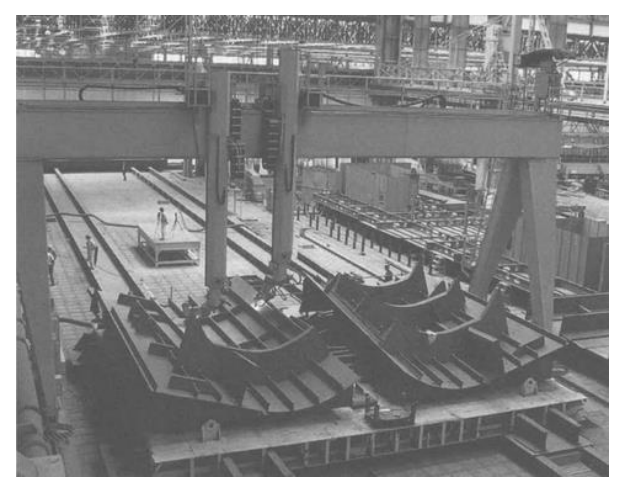

Figure 2 The mobile bed-Jigs at Italian Fincantieri shipyard

Processing in Fixed -Location mode has been put into practice for a long time, and adjusted with the change of new technology or new environment, which is quite scientific. So, the main body of the processing flow of the curved block assembly line retains the current process, and the following changes are made to the processing flow only according to the characteristics of the Flow-Line and the application of advanced equipment, changes are as follow:

1. Considering that some of the curved panel members only have longitudinal parts, which are simpler than others, it is decided that the this curved panels should be moved out in advance in the assembly line, so as not to affect the subsequent production of other groups. Therefore, the assembly and welding of the curved panel must be divided into longitudinal parts welding and girder assembly \& welding, and buffer area displacement should be set after the longitudinal assembly \& welding. In order to apply the advanced welding machine, robot is further divided into longitudinal parts welding and girder welding.

2.The movable bed-jigs can be adjust to the desired shape according to the data obtained from the production design, so the manufacturing process of the bed-jigs is omitted.

3.Considering the actual situation in china and the production requirements of Flow-Line, automation or intelligent equipment is also applied in the curved plate welding and marking inspection process to ensure the production efficiency and quality control of the curved panel.

After the above process changes, the curved block production process is shown in the Figure 3.

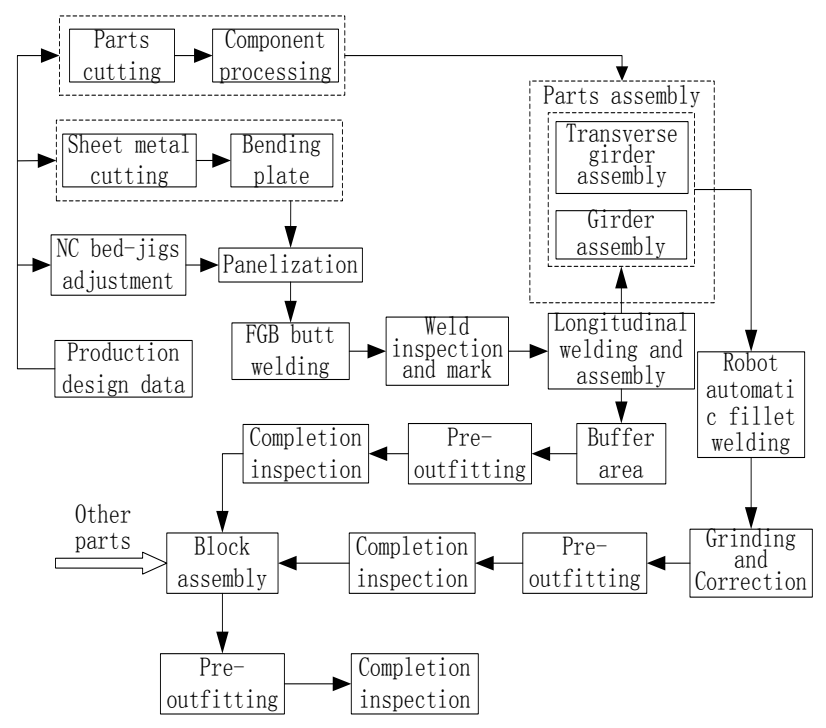

Figure 3 Curved block production process after reformation

\section{B. Workshop layout of curved panel subassembly shop}

In order to apply the subassembly Flow-Line of curved panel to the actual production of shipyard, this paper designs the layout of curved panel subassembly shop on the basis of current curved block assembly shop of a shipyard in China and the intellectualized assembly shop abroad. Because of the large volume and the large quantity of the curved panel production, the author thinks that the curved panel subassembly line can be separated from the manufacturing workshop of curved block, and set up a separate curved panel subassembly shop. At the same time, the large production of curved block can be concentrated in the remaining manufacturing curved block assembly shop. So as to keep the workshop occupying the ground under the condition of constant product, the fluidized production in curved panel is realized. The final formation of the curved subassembly shop layout is shown in the Figure 4. 


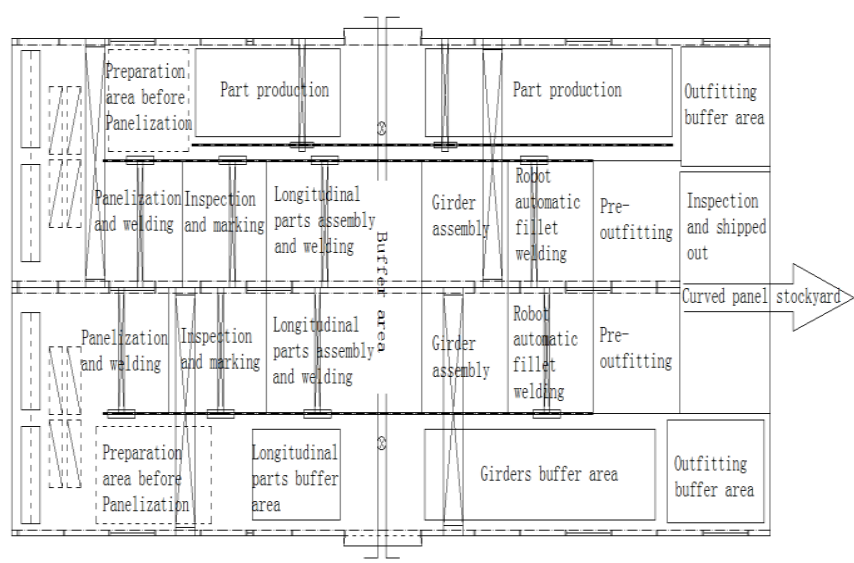

Figure 4 Layout of curved panel subassembly shop

A horizontal buffer zone is set in the middle of a curved panel subassembly shop, only the curved panel with longitudinal parts can be transported. At the same time, the space for the operation of large-scale intelligent equipment is left in corresponding workstation, the specific design of the curved panel subassembly shop is as follows:

1.Considering the production rhythm of balanced curved block and planar block, as well as the state of full load of shipyard in the future, two parallel curved panel subassembly lines are set up in the manufacturing workshop of curved panel. In order to effectively adjust the production of assembly lines, the two Flow-Line are connected in the transverse buffer zone, which is to lay the tracks needed for the movement of $\mathrm{NC}$ bed-jigs in the transverse region, connecting the tracks of two Flow-Line and extending to the exit.

2. In the area beside the assembly line, the buffer is set up. The set up results are shown in Figure 4.

\section{MODELING AND SIMULATIN}

Establishing curved panel subassembly shop is a complicated system engineering. The transformation of the curved block assembly line will inevitably cost a lot. Therefore, the design of the subassembly Flow-Line of curved panel must undergo strict demonstration and inspection before it can be applied in practice. The most direct and effective way is to simulate the production system and test it, but the cost of physical model is too high. On the other hand, Learning model can't solve such complex system problems. The problem seems to be in a deadlock. However, in recent years, the computer-based virtual simulation technology provides a new solution to this problem. Virtual simulation technology can simulate the operation of production system in the computer virtual environment and predict its system state, thus providing a basis for analyzing and evaluating new production system. Plant Simulation is one of the most comprehensive simulation software in computer simulation. It has been widely used in many fields at present. So Plant Simulation is chosen as the platform to model and simulate the curved block production line after reformation, and to verify the rationality of the curved panel subassembly shop.

\section{A. Modeling of reformed curved panel subassembly shop}

Use Plant Simulation software to established the simulation model of curved block production line, the model as shown in Figure 5. Figure 6 is the control panel of the model.

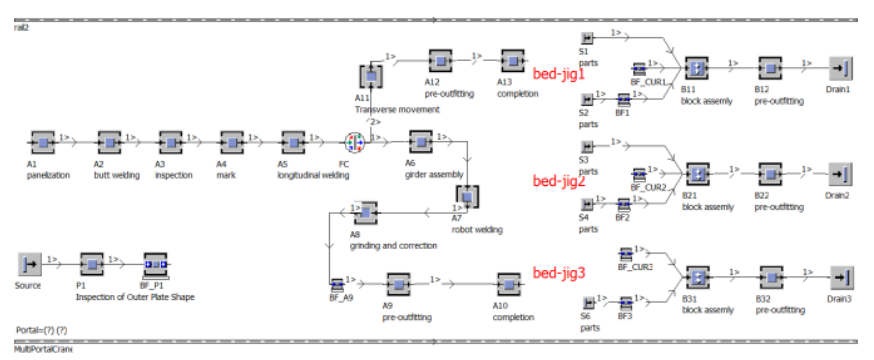

Figure 5

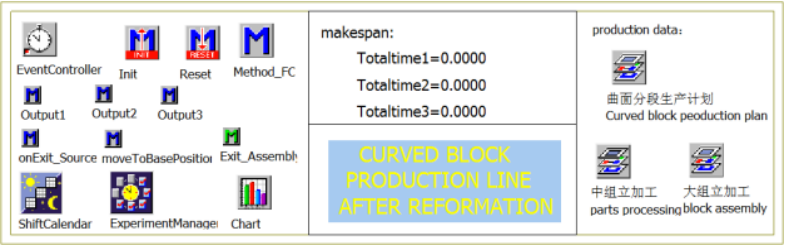

Figure 6

In order to evaluate the influence of the subassembly Flow-Line of curved panel on the whole curved block production line, the model also simulates the curved block assembly. Each virtual workstation has been indicated in the model. BF_CUR1, BF_CUR2 and BF_CUR3 are used to simulate the buffer area in curved form. The default of the model is that the components are supplied on time and the starting time is zero.

In order to evaluate the running state of the subassembly Flow-Line of curved panel more scientifically, the current curved block production line as shown in Figure 7 is established as a bridge to compare the reformed curved block production line with the current actual production line. Figure 8 is the control panel of the current block production model.

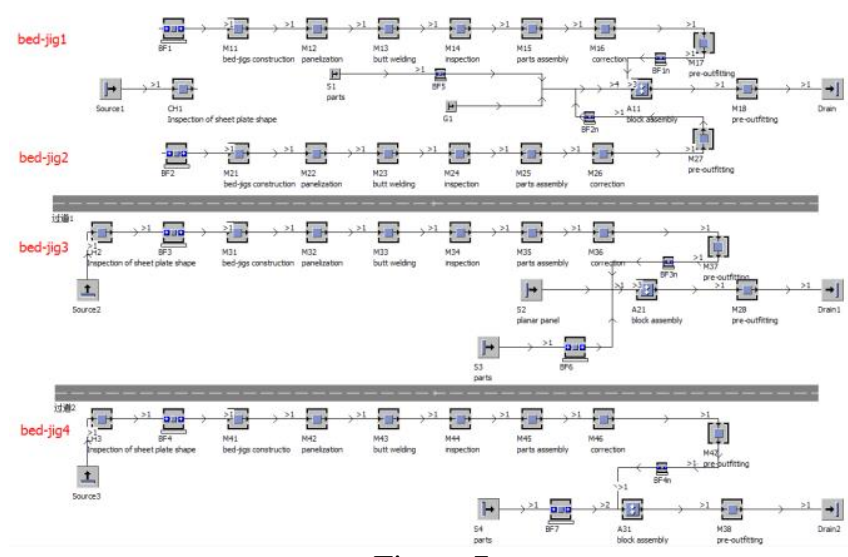

Figure 7

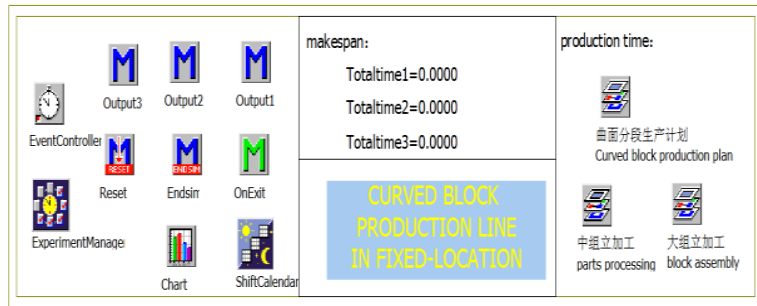

Figure 8

\section{B. Simulation of the model}

Taking a cycle Bed-jig execution schedule of a Shanghai shipyard's curved block production as an example, and put the data into above model. Table 1 is the monthly Bed-jig execution schedule of the yard. 
Table1 Bed-jig execution schedule

\begin{tabular}{cccc}
\hline $\begin{array}{c}\text { Bed-jigs } \\
\text { No }\end{array}$ & $\begin{array}{c}\text { Block } \\
\text { No }\end{array}$ & Start & End \\
\hline & 102 & November 16th & January 10th \\
& 102 & November 16th & January 3th \\
A-1 & 624 & December 17th & January 8th \\
& 624 & December 24th & January 15th \\
& 102 & December 30th & March 8th \\
& 102 & January 6th & March 10th \\
\hline & 803 & December 30th & March 6h \\
& 182 & December 30th & January 28th \\
& 803 & December 30th & February 28th \\
A-2 & 182 & January 12th & February 5th \\
& 162 & January 12th & March 4h \\
& 162 & February 17th & March 1h \\
& 162 & February 23th & March 20h \\
\hline & 201 & October 19th & December 6th \\
& 201 & November 19th & December 21th \\
A-3 & 622 & December 7th & January 8th \\
& 622 & January 3th & February 25th \\
& 622 & January 22th & March 11h \\
\hline
\end{tabular}

On the basis of the above bed-jigs execution schedule, combined with the standard engineering drawings of

blocks, the working hours of each workstation in curved block production line are estimated by the unit of assembly statistics, which is also consistent with the on-site time management based on the task package and the dispatch order. Meanwhile, for each workstation in subassembly Flow-Line of curved panel, by referring to the production experience of foreign advanced curved block production lines and the processing parameters of related equipment at home and aboard, the basic working time of each workstation is first worked out, then, The processing time of each station in the subassembly Flow-Line of curved panel is obtained by the basic working time. Table 2 is the basic working time of some workstations in curved panel subassembly Flow-Line. Put the processing time into the model and run the model for simulation.

Table2 Basic working time

\begin{tabular}{|c|c|c|c|}
\hline No & workstation & Work content & Operation time \\
\hline 1 & Panelization & $\begin{array}{c}\text { NC bed-jigs } \\
\text { adjustment and shape } \\
\text { detection }\end{array}$ & $\begin{array}{c}\text { 70min/ } \\
\text { subassembly }\end{array}$ \\
\hline 2 & Butt welding & FGB welding & $\begin{array}{l}\text { Seam length } \mathrm{x} \\
6 \mathrm{~min} / \mathrm{m}\end{array}$ \\
\hline 3 & Marking & $\begin{array}{c}\text { Drawing structural } \\
\text { line on the curved } \\
\text { plate }\end{array}$ & $\begin{array}{c}\text { Structure line } \\
\text { length } \times 2 \mathrm{~min} / \mathrm{m}\end{array}$ \\
\hline 4 & Buffer area & $\begin{array}{c}\text { Remove the curved } \\
\text { panel with } \\
\text { longitudinal parts } \\
\text { only }\end{array}$ & $\begin{array}{c}\text { 40min/ } \\
\text { subassembly }\end{array}$ \\
\hline 5 & Parts assembly & $\begin{array}{c}\text { Hoisting parts to } \\
\text { designed position } \\
\text { and location welding }\end{array}$ & $\begin{array}{l}\text { Longitudinal } \\
\text { parts length } x \\
6 \mathrm{~min} / \mathrm{m}\end{array}$ \\
\hline \multirow[t]{2}{*}{6} & $\begin{array}{l}\text { Robot automatic } \\
\text { fillet welding }\end{array}$ & Fillet seam welding & $\begin{array}{l}\text { Fillet weld seam } \\
\text { length } \times 5 \mathrm{~min} / \mathrm{m}\end{array}$ \\
\hline & $\begin{array}{l}\text { Completion } \\
\text { inspection }\end{array}$ & $\begin{array}{l}\text { Completion } \\
\text { inspection }\end{array}$ & $\begin{array}{c}\text { 60min/ } \\
\text { subassembly }\end{array}$ \\
\hline
\end{tabular}

\section{Analysis of simulation results}

Firstly, the processing data of H1296_201, H1305_803 and H1305_102 block are selected and input it's data into the current curved block production line simulation model. The simulation results are 46 days 8 hours, 65 days 8 hours and 52 days 10 hours. Compared with the actual completion time in Table 1, the error of the three blocks production time is within 2 days, which is a reasonable error range. Therefore, the model of the current curved block production line is relatively reliable.

Then the working hours of A-1, A-2 and A-3 execution schedule are input into the simulation model of the curved block production line after the curved panel subassembly line modification and the current curved block production line respectively. It is obtained that the completion time of bed-jigs A-1 is 142 days and 14 hours for the former and 156 days and 10 hours for the latter (which is quite different from the time in the bed-jigs execution plan, mainly because the model does not consider parallel construction and waiting for construction). The completion time of A-2 is 120 days 14 hours and 141 days 11 hours respectively, while A-3 is 100 days 16 hours and 114 days 10 hours. It can be seen that the production period of curved block manufacturing can be greatly shortened by the subassembly Flow-Line of curved panel. The completion time before and after modification is shown in Figure 9.

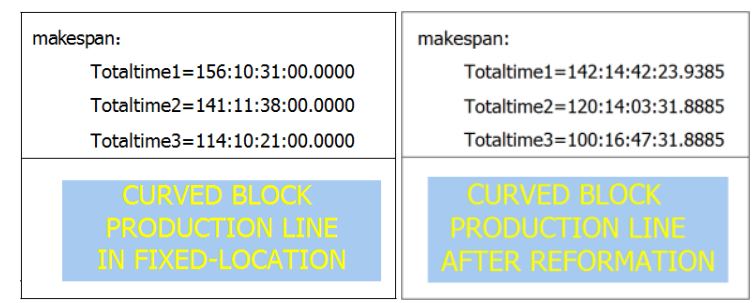

Figure 9

\section{CONCLUTION}

Combining with the requirements of shipyards in the era of intellectualization and the actual situation of Chinese shipbuilding enterprises, this paper designs the subassembly Flow-line of curved panel. By Fluidized production of key intermediate products in curved panel, the production efficiency of curved block assembly is improved, and the automation and intellectualization of curved block production line are promoted, so as to enhance the competitiveness of shipbuilding industry. The rapid development of virtual simulation technology in recent years has provided a reliable and convenient experimental platform for evaluating the running state of the curved panel subassembly Flow-Line. Therefore, the computer simulation software Plant Simulation is used to model and simulate the curved panel subassembly line and the corresponding curved block production line, in order to make the simulation results more comparable, the current curved block production line is also introduced. The results of modeling and simulation show that the subassembly Flow-Line of curved panel can not only improve the efficiency of curved block, but also greatly reduce the blockage in the production line. It proves that the subassembly Flow-Line designed in this paper meets the development needs of Chinese shipyards to a large extent and has high reference value. 


\section{REFERENCES}

[1] Adhesion Adhesives \& Sealants Group. Industry 4.0 and its importance for joining technologies[J]. Adhesion Adhesives \& Sealants, 2017, 14(1): 44-44.

[2] Lu Delong. It's urgent! Intelligent shipbuilding arrows are on the chord[J]. Guangdong Shipbilding,2017, 36(3): 4-7.

[3] Li Yongbo. Application Study of Robot Production Lines in Smart shipbuilding[J]. SHIP ENGINEERING, 2017, 39(10): 95-99.

[4] ZHANG Zhi-ying, JIANG Zhi-bin, CHEN Qiang etc. Research on Virtual Flow-Line and It's Key Technologies for Manufacturing Curved Module of Ship[J]. SHIPBUILDING OF CHINA, 2005(03): 112-116.

[5] LI Jing-sheng, WANG Ai-min, TANG Cheng-tong etc. Spatial scheduling method for ship curve block construction based on virtual flow style[J]. Computer Integrated Manufacturing Systems, 2014, 20(08): 1903-1913.

[6] Tang Weidong. The Research on the Scheduling Problems in Curved Blocks Shipbuilding[D]. Harbin Engineering University, 2015.

[7] MA Zujie. Research on the Strategy of Production Operation in Q Shipbuilding Company[D]. South China University of Technology, 2017.

[8] GU Yong-feng, YANG Chen, SHE Jian-guo. Research on three-dimensional modeling method of flexible bracket based on group technology in simulation system[J]. SHIP SCIENCE AND TECHNOLOGY, 2015, 37(06): 127-129.

LI Ming-ming School of Naval Architecture \& Ocean Engineering, Jiangsu University of Science and Technology, Zhenjiang, Jiangsu, China Phone No 8618851407805

WANG Yue School of Naval Architecture \& Ocean Engineering, Jiangsu University of Science and Technology, Zhenjiang, Jiangsu, China. Phone No 8613952807905

LI Cui-cui School of Petrochemical and Energetic Engineering, Zhejiang Ocean University, Zhoushan, Zhejiang, China. Phone No 8613655804765 